\title{
Predicts the Factors Influencing on Behavior of Body Management in Female Students (Original Research)
}

\section{T. Mohammadinia (Tayebeh Mohammadinia), R. Z. Mehrjardi (Raheleh Zare Mehrjardi)}

Department of Social Sciences, Payame Noor University, Tehran, IR

\section{E-mail address:}

researchpnu@yahoo.com

\section{Reprint address:}

Tayebeh Mohammadinia

Department of Social Sciences, Payame Noor University, Tehran, IR

POB 19395-4697 Tehran

IR

Suource: Clinical Social Work and Health Intervention Pages: $61-68$
Volume: 8

Issue: 4

\section{Reviewers:}

Gunther Dorfmeister

Vienna General Hospital, Vienna, AT

Johnson Mawole

Department of Sociology and Statistics, University of Mwanza, TZ

\section{Key words:}

Body Management. Diversityism. Distinction-Seeking. Females. Modernism.

\section{Publisher:}

International Society of Applied Preventive Medicine i-gap

CSWHI 2017; 8(4): 61 - 68; DOI 10.22359/cswhi_8_4_07 @ 2017 Clinical Social Work and Health Intervention

\section{Abstract:}

This study aimed to investigate the relation between body management and body satisfaction, diversityism, modernity, attention-drawing and distinction-seeking and sought to identify the predictability degree of these variables through quantitative and survey methods as well as questionnaire tool. Their effects on body management are considerable since they play an important role in society and in family. 
The tendency of young girls to control their weight, to be in shape; to consume cosmetics increases day-to-day. Theoretical framework of research was a compilation of theories of Sociology and Psychology. The statistical population consisted of female students of Payame Noor University of Abade in the academic year 2014-2015. In this study, 150 questionnaires were distributed among the students and 130 samples were selected, which were thirty times more than the main variables of the study. Pearson Correlation was used for data analysis and stepwise multiple regression was used to predict. Previous studies were reviewed for determining different dimensions of body management, which finally were summarized in characteristics: personal and health care (alpha= $0.81)$; interest in fitness (alpha $=0.70)$; weight control (alpha $=0.80)$. Totally, body management was assessed by 36 items in which Cronbach's Alpha was 0.79. The results showed that diversityism ( $\mathrm{t}=4.182)$, distinction-seeking $(\mathrm{t}=3.866)$ and modernity $(\mathrm{t}=3.879)$ were related to body management directly and positively and were not related to body satisfaction and attention-drawing. Finlay Stepwise regression results showed that there was Correlation between diversityism and body management in female students. At this stage, the coefficient of determination $\left(\mathrm{R}^{2}\right)$ was 0.120 and in the second stage, with the introduction of modernity, the coefficient of determination $\left(\mathrm{R}^{2}\right)$ was equal to 0.164 , which explained about $17 \%$ of body management changes. Despite the primary assumption, body satisfaction and drawing attention were not in significant relationship with body management.

A new attention to the body and recirculation of its issues in sociological texts in two recent decades have revived debates over subject matters such as identity; social movements; consumer culture; lifestyle; ethics, to the extent one can apply the metaphor of "social body" (21) or "body age" (8) in line with metaphors like return to culture or return to language in this regard (pointing to prevalence of postmodern or post-structural thoughts and theories). Several processes are about youth in regard to importance and promoted status of body and body culture, both on structural and ethical levels, such as: growth in health technology; sports and nourishment; fashion and cosmetic industries; ever-increasing interests in juvenility; priority of consumption; individualism; attention to differences in lifestyle; mass media and mass culture 'with special emphasis on fresh and attractive body'; popular culture.

With modernity, globalization, and development of technologies relevant to body, body management has become more significant than the past (5). In fact, consumer-oriented identity and body-oriented consumption in this new and globalized society have made body managements such as makeup, diet, cosmetic surgery, etc. dominant practices and behaviors among women $(16 ; 4)$. Body and its management are cultural issues connected to social values and norms, in a way members modify their behavior with the changes in cultural elements and components. Self-presentation and self-ornamentation are important issues for women. Women are psychologically heterosexual 
so that they are inclined into self-ornamentation more than men (18). The need for self-presentation in human being causes tendencies to different kinds of ornamentation and for fashion and making distinctions as well. In classifying needs, Alexander Mary concerns with 'self-presentation' as a need and defines it: "the need for self-presentation is to draw attention, to influence, to attract, to arouse curiosity, to entertain" (3). The study entitled "Does It Make Me More Beautiful? A Discussion over Cosmetic Surgery" by Zare et al. (2014), indicated that positive attitude toward cosmetic surgery confirms human agency for self-control and independence. Nonetheless, ever-increasing tendency of men for cosmetic surgery in Iran approves the fact that lack of confidence in transsexual and patriarchal system has found its new men victims to whom new standards of beauty have imposed. In addition, imitating cultural standards of beauty is inevitable since individuals who do not follow may be abandoned from communities (22).

Siti Zulaikha et al. (2015), in their study entitled "Dangerous Raw Material in Cosmetics, Personal Care, and Safety" concluded that with global increases in demands for cosmetics among adolescences and adults, the awareness and responsiveness for their safety have increased as well. They aimed to show hygienic and harmless materials can be used in cosmetics or other personal care productions. Cosmetics are composed of preservatives, perfumes, and heavy metal impurities. Their study in fact suggested people should be more informed about materials used in cosmetics and their side effects (20).

Khosheghbal et al. (2015), in their paper "Analyzing Relationship between Perfectionism and Body Image Dissatisfaction among Demanders of Cosmetic Surgery, The Role of Primary Incompatible Scheme" concluded that there is a significant relationship between demands for nose cosmetic surgery with body image dissatisfaction, perfectionism, and primary incompatible schemas (14). The results of the study "Body Management and Social Acceptance (Case Study: Students of Islamic Azad and Payame Noor University of Zanjan, Iran)" by Shekarbeigi and Amiri specified the mean of body management for female students is 83.46 and it is 72.66 for male students, that confirm female students manage their body more than male students. Totally, 89.7 percent of variance or spread of body management variable were determined through independent variables (19). The results of the study "Lifestyle and Body Management" by Khajeh Noori, et al. (2011), indicated that modern lifestyles influenced by sport, music, leisure, new participations, religious, traditional music all together define 45 percent of women's body management and 30.3 percent of their shape change management (13). Having considered body management as an element in lifestyle, Karami Qehi and Zadsar, (2013), in their study "Assessing the Relationship between Religiosity and Lifestyle (Case Study: 20 years-old or older females living in Tehran) concluded that there is high Correlation between religiosity and lifestyle and there is also a weak relationship between age and religiosity (11). Ghaderzadeh, et al. (2012), in their study "Tattoo and Reflexive Individual Construction" considered tattoo as body management and design that has obtained social and signifying function through which individuals express their individual, mental, and sexual identity (7).

Results of the study by Heidarkhani et al. (2013), in The Relationship between Elements of Cultural Capital and Body Management in Women indicated that cultural capital (behaviors and appearances, objectified, and internal knowledge), economic and marital status have a positive and direct relationship with body management in women (9). The findings of the 
study Similar Members in Similar worlds: Analyzing the Effect of Globalization in Body Management by Fathi and Rashtiani, (2013), designated a direct and significant relationship between globalized media and communicative technologies through implication of sender's culture (acculturation of addressee); spread of consumer culture; variety and renovation; globalized western popular culture; spread of individualism and self-education; education from and to others; and mutual feedbacks have a direct and significant relationship with body management, but there is not any relationship between body management and theorizing (6). The findings of the study Analyzing Effective Social Factors on Women's Tendency toward Body Management in Recent Three Decades by Mirzai et al. (2013), indicated that there is a significant relationship between marital status; job and occupation; media; spiritual growth and self-actualization; eating habits; responsibility for healthiness; intersubjective relationships; fashion; management of stress; sports and exercises with tendency to be in shape; but a significant relationship was not observed between age; education; socio-economic status with the tendency to be in shape (17).

The findings of by Khajeh Norri and Parnian, (2014), indicated that variables of rethinking, modern lifestyle new technologies in the domains of communication and information; sociable lifestyle; awareness of globalization; sexuality have positive and significant relationship with body management (12). New technologies in the domains of communication and information; modern lifestyle; sociable lifestyle; and rethinking totally defined $52.2 \%$ of the changes in body management. Adibi Sedeh and Jalali Akordi, (2015), in their study Body Management and National Identity in Youth (Case Study: The Young in Sari) concluded that there is a negative and inverse relationship between body management and national identity in youth. The results of regression analysis indicated that independent variables totally define $23.4 \%$ of changes in national identity (1).

\section{Hypothetical Framework of the Study}

A synthesis of psychological and sociological theories are considered for the hypothetical frame-work of the present study. Maslow's hierarchy of needs is firstly considered for a psychological approach. In this theory, human needs are categorized in five levels that respectively are:

- Physiological needs: that are necessary for living: food, clothing, sex, health, and housing.

- Safety needs: non-violence, security, and non-deprivation are essential needs in this regard; in other words, this level is concerned with protection in the present and future.

- Social needs: or love and belonging; human being as a socially-oriented person who attempts to operate in relationships with other human beings.

- Esteem: this is firstly from the individual to himself/herself; then it is achieved by others in respect to a person. If a person cannot obtain respect and esteem by proper manners, he/she may tend to draw attention through violation from cultural and social norms.

- Self-actualization: it is the actualization of potential talents and abilities, as Maslow states what a human being can be must be attained (2).

If an individual is not satisfied with his physical and health condition in the first level of needs, he/she may attempt to draw attention in order to stimulate their respect and admiration toward himself/herself (15). On the other hand, this study relies on sociological 
theories introduced by Goffman, Bourdieu, and Weber. Max Weber widened class distinction and its relevant issues. His distinction between status and class along with related issues on production; life chance; consumption; and lifestyle have been influential in further development of theories pertinent to consumption and lifestyle.

A significant point is the role of sex in attention to body. Women have been concerned with their body and physicality more than men. Bourdieu believes body is a physical capital that concerns with social status and forms of distinction. Considering body as a physical capital, Bourdieu connects identities with social values in regard to size, shape, and appearance (3).

On the other hand, Goffman reflects on face as a significant issue in social and face-to-face dealings and interactions. Social face is a public face which is required to continuous changes in the masks it represents. Makeup is a mean for attaining this mask. It is just in severe emotional states, loneliness, and among friends that this mask or makeup disappears, and the person is in his/her real state.

This study aims to analyze the effects and predicting abilities of variables variety-seeking, body satisfaction; individuation; modernity; and drawing attention on body management among female students. Their effects on body management are considerable since they play an important role in society and in family. The tendency of young girls to control their weight, to be in shape, to consume cosmetics increases dayto-day. Unlike Europe, women in Iran tend to consume cosmetics and do makeups. Women in Iran spend nearly 1,630 million euros annually for imported or smuggled cosmetics. Consuming cosmetics is not related to special class or for specific age; women in Iran consider it part of their essential life. On the other hand, the age of using cosmetics is now 15 in Iran, in contrast to developed societies in which older women tend to cosmetics since they have lost their fresh and young skin and body.

\section{Research hypothesis}

Diversityism of female students has a significant effect on their body management. The body satisfaction of female students has a significant effect on their body management. Distinction-seeking of female students has a significant effect on their body management. Modernism of female students has a significant effect on their body management. Drawing attention by female students has a significant effect on their body management.

\section{Methodology}

The methodology of this study is quantitative that applies Correlation analysis, and it utilizes survey research technique. The statistical population of this study are female students in Payame Noor University of Abadeh during the year 2014-2015: it is 120 persons, thirty times more than principal variables of the study that for assurance increased to 130 persons.

\section{Tools for Analysis}

A questionnaire was used for collecting data; its validity is nominal. What is meant by nominal is realizing the validity of questionnaire's factors and characteristics through referring to reviewers. Acceptable reliability was accomplished by a pre-test (50 questionnaire). The harmony of items and the internal compatibility of the questionnaire were provided by Cronbach's Alpha. Each effective variable was assessed by six items that Cronbach's Alpha for all is 0.75 . A dependent variable is body management which covers continuous observation and changes in the physical body. In other words, all characteristics and behaviors that 
cause distinction in an individual's physical appearance in contemporary life are considered as body management. It is analyzed through weight control; surgery; personal and health care. Previous studies were reviewed for determining different dimensions of body management that finally were summarized in characteristics: personal and health care (Alpha: 0.81); interests in fitness (0.70); weight control (0.80). Totally, body management was assessed by 36 items that Cronbach's Alpha was 0.79 .

\section{Data Analysis}

For this purpose, 150 questionnaires were distributed among the students of Payame Noor University of Abade. After analyzing 130 questionnaires, SPSS software were used for data entering and coding. Pearson Correlation was used for data analysis and stepwise multiple regression was used to predict.

\section{Results}

Descriptive statistics revealed, $15.4 \%$ considered themselves to the lower class; amount of makeup was in the wedding ceremony and subsequent party and university.

Pearson Correlations were used to assess the relationships between variables. Hypothesis test results is shown in Table 1.

In the first hypothesis test, Pearson Correlation coefficient for diversityism and body management was 0.347 , which this relationship was significant $(\mathrm{p}<0.01)$.

In the second hypothesis test, Pearson Correlation coefficient for body satisfaction and body management was 0.071 , which this relationship was not significant.

In the third hypothesis test, Pearson Correlation coefficient for distinction-seeking and body management was 0.323 , which this relationship was significant $(\mathrm{p}<0.01)$.

In the fourth hypothesis test, Pearson Correlation coefficient for modernism and body management was 0.324 , which this relationship was significant $(\mathrm{p}<0.01)$.

In the fifth hypothesis test, Pearson Correlation coefficient for draw attention and body management was 0.114 , which this relationship was not significant.

Table 1: Pearson Correlation test and body management.

\begin{tabular}{|l|l|l|}
\hline Variables & The Correlation coefficient & Significance level \\
\hline Diversityism & $0.347 * *$ & 0.000 \\
\hline Body satisfaction & 0.071 & 0.421 \\
\hline Distinction-seeking & $0.323 * *$ & 0.000 \\
\hline Modernism & $0.324 * *$ & 0.000 \\
\hline Draw attention & 0.114 & 0.197 \\
\hline \multicolumn{2}{|c|}{$* *=\mathrm{p}<0.01$}
\end{tabular}

$80 \%$ to middle class; $4.6 \%$ to high-class. Based on the results $22.3 \%$ at the time of purchasing; $45.4 \%$ in the party; $83.1 \%$ in the wedding party; $18.5 \%$ in the recreation and pilgrimage; and $32.3 \%$ attending university were self-make-up. Generally, the most

\section{Statistical Analysis}

Multiple Regression Analysis of step by step was utilized in this study. The regression model of body management for female students indicates that regression analysis followed two steps. 
The first variable involved in regressed equation in variety-seeking. The results showed that there was correlation between diversityism and body management in female students. At this stage, the coefficient of determination $\left(\mathrm{R}^{2}\right)$ was 0.120 and in the second stage, with the introduction of modernity, the coefficient of determination $\left(\mathrm{R}^{2}\right)$ was equal to 0.164 , which explained about $17 \%$ of body management changes. Variables of body satisfaction, distinction-seeking, drawing attentions were not included into the equation. The value and measure of $\mathrm{F}$ are significant (12.481), and this indicates at least one of the independent variables is effective in predicting a dependent variable (Table 2).
The results of this study indicated that variables of variety-seeking, individuation, and modernity are in significant relationship with body management that are in line with findings by Khajeh Noori and Parnian (2014) (12), Ghaderzadeh et al. (2012) (7), Khajeh Noori et al. (2011) (13), Heidarkhani et al. (2013) (9), Fathi and Rashtiani (2013) (6), Mirzai et al. (2013) (17), and Khoshedgbal (2015) (14), but the results of this study are not in line with findings by Zare et al. (2014) (22) and Shekarbeigi and Amiri, (2011) (19). Despite primary assumption, body satisfaction and drawing attention are not in significant relationship with body management.

Table 2: Elements and variables within the equation to predict the managing body.

\begin{tabular}{|l|l|l|l|l|l|l|}
\hline The level & Variable & $\mathrm{B}$ & Beta & $\mathrm{t}$ & $\mathrm{p}$ & $\mathrm{R}^{2}$ \\
\hline 1 & Diversityism & 0.319 & 0.262 & 2.996 & 0.003 & 0.120 \\
\hline 2 & Modernism & 0.236 & 0.226 & 2.587 & 0.011 & 0.164 \\
\hline & $\mathrm{p}=0.000$ & $\mathrm{~F}=12.481$ \\
\hline
\end{tabular}

\section{Dissection and Conslusion}

In this study, several variables were studied in relation to body management in female students. Dramaturgical Theories by Goffman, Bourdieu, and Weber provided the hypothetical framework of the study on body management. In dramaturgical theory of Goffman, individuals are in role play, and their physical appearance is determining for their roles. On the other hand, body capital, in terms of Bourdieu, is the result of interaction among social status; habitus and taste, which provides individuals with symbolic capital, subculture possibilities and distinctions. Bourdieu analyzed different groups in society that are distinctive through consumption patterns that determine lifestyle.

\section{References}

1. ADIBI SEDEH M, JALALI AKORDI SH (2015) National identity and management body in youth. Journal of Sociological Studies, 17(5): 9-32.

2. ALVANI S M (2007) Public Management. Thirtieth Publishing. Publisher: Ney. Tehran, Iran.

3. BABAMIRI M, GHASEMI D, ZARE R, ABBASI M (2010) Social and psychological factors influencing on cosmetics usage by female students. Journal of Skin and Beauty, 2(4):193-202.

4. BOURDIEU P (2002). Sport's action and social practices. 20: 12-26.

5. DULINA NV, KARGAPOLOVA EV, STRIZOE AL (2017) Young people in 
modernization processes: assessment of the state of affairs (case study of Southern Federal District regions). Economic and Social Changes: Facts, Trends, Forecast, 10(2): 130-149.

6. FATHI S, RASHTIANI A (2013) Similar organs in the world: investigate the role of globalization in body management. Journal of Social Development Studies, 5(3): 79-90.

7. GHADERZADEH O, MOHAMMADPOUR A, GHOLAMI A (2012) Tattoos and construction of a reflector. Iranian Journal of Social Problems, 1(2): 160-185.

8. HANCOCK P, HUGHES B, JAGGER E, PATERSON K, RUSSELL R, TULLE-WINTON E, TYLER M (2000) The body culture and society, Buckingham: Open University Press.

9. HEIDARKHANI H, HAJIAQAI L, RAHMANI G (2013) The relationship between cultural capital and body management in women. Journal of Women and Culture, 8 (4): 55-69.

10. ILYIN VA (2015) Public administration efficiency and the aggravation of public health issues. Economic and Social Changes: Facts, Trends, Forecast, 6(42):11.29.

11. KARAMI QEHI MT, ZADSR Z (2013) Assessment to evaluate the relationship between religiosity and lifestyle (Case study: The 20-year-old women living in Tehran). Women in Arts and Culture, 5(1): 85-101.

12. KHAJEH NOORI B, PARNIAN L (2014) The relationship between cultural globalization and body management (Study of Women in Kermanshah). Applied Sociology, 25(3): 163-180.

13. KHAJEH NOORI B, ROHANI A, HASHEMI S (2011) Lifestyle and body management. Journal of women Sociology (Women and Society), 2(4).

14. KHOSHEGHBAL M, EESAZADEGHAN A, MIKAELI MANEE F (2015) Examination of the Relationship between Perfectionism and Body Image Dissatisfaction in Nose
Beauty Surgery's Applicants: Role of Early Maladaptive Schemas. International Journal of Psychology and Behavioral Sciences, 5(3): 109-114.

15. LIM YH, KIM SY, CHOI M (2012) A Study on the Skin Care and Body Management Behaviors and Using Condition of Its Shops in Middle-Age Women in Their 40s 50s in Busan and Gyeongnam, Republic of Korea. Korean Journal of Aesthetic Cosmetic, 10(1): 41-49.

16. MALSKHOVA NN (2014) Consumer in the innovation economy: sociocultural aspects offormation and functioning. Economic and Social Changes: Facts, Trends, Forecast, 6(36): 213-224.

17. MIRZAI SM, ZANJANI H, GHORBANALIPOUR S (2013) Social Factors influencing the propensity of women to the body management in Iran over the past three decades. Journal of Social Development Studies, 5(4): 99114.

18. RUDD NA, LENNON SJ (2000) Body Image and Appearance-Management Behaviors in College Women. Clothing and Textiles Research Journal, 18(3): 152-162.

19. SHEKARBEIGI A, AMIRI A (2011) Body management and social acceptability (Case study: male and female students of Payame Noor and Islamic Azad University of Zanjan). Journal of Sociology Studies, 2 (3): 85-108.

20. SITI ZULAIKHA R, NORKHADIJAH SI, PRAVEENA SM (2015) Hazardous Ingredients in Cosmetics and Personal Care Products and Health Concern: A Review. Public Health Research, 5(1): 7-15.

21. TURNER B (1996) The body and society, London: Sage.

22. ZARE B, JAVADI F, NASERI S (2014) Does It Make Me Beautiful? A Focus Group Discussion on Cosmetic Surgery. International Journal of Applied Sociology, 4(5): 126-132. 